\title{
Experimental Study on Permeability Anisotropy of Unsaturated Compacted Loess
}

\author{
Yan Zhou Hao $\mathbb{D}^{1},{ }^{1}$ Lei Cheng, ${ }^{2}$ and Wen Fang Xiao ${ }^{3}$ \\ ${ }^{1}$ School of Civil and Transportation Engineering, Henan University of Urban Construction, Pingdingshan 467036, Henan, China \\ ${ }^{2}$ College of Engineering Management and Real Estate, Henan University of Economics and Law, Zhengzhou 450046, \\ Henan, China \\ ${ }^{3}$ Guiyang University, School of Urban-Rural Planning and Civil Engineering, Guiyang 550005, Guizhou, China
}

Correspondence should be addressed to Yan Zhou Hao; 30010508@hncj.edu.cn

Received 3 May 2021; Revised 4 November 2021; Accepted 29 December 2021; Published 19 January 2022

Academic Editor: Angelo Aloisio

Copyright (c) 2022 Yan Zhou Hao et al. This is an open access article distributed under the Creative Commons Attribution License, which permits unrestricted use, distribution, and reproduction in any medium, provided the original work is properly cited.

\begin{abstract}
This study investigates the permeability characteristics of unsaturated compacted loess by focusing on the anisotropy parallel and perpendicular to the compaction. Three tests are conducted on compacted loess: permeability test, soil-water characteristic curve test, and scanning electron microscope (SEM) test. Samples are maintained and tested at different dry densities under optimal moisture conditions. Test results showed that the horizontal saturated permeability coefficient of compacted loess was larger than in the vertical direction, showing obvious anisotropy. Based on the saturated permeability coefficient, the permeability coefficient of unsaturated compacted loess can be predicted according to the soil-water characteristic curve fitted using the van Genuchten model combined with the Childs and Collis-Geroge model. The relational formula was established between the unsaturated permeability anisotropy ratio and the matrix suction through introducing a pore connectivity-tortuosity parameter, which represents the relationship between unsaturated permeability anisotropy ratio and matrix suction. The difference of pore characteristics between horizontal and vertical directions of compacted loess is the main reason for the permeability anisotropy.
\end{abstract}

\section{Introduction}

The gully is a unique landform common to loess areas that limits city development and expansion. Some cities in China, including Yan'an, Lanzhou, and others, have begun largescale hill-cutting, gully filling, and artificial land-building engineering in order to facilitate city expansion. In addition, highway, railway, and airport construction in loess areas requires filling to make up for the shortage of construction land. Undisturbed loess commonly has a macroporous structure and is undercompacted and collapsible, which has adverse consequences for foundation construction. Compaction is the primary method employed to improve the mechanical properties of compacted loess and prepare loessfilled construction sites. Permeability is an important property of loess. Water infiltration weakens compacted loess; therefore, examining the permeability of compacted loess is of great significance to large-scale filling foundations, roadbeds, and slopes in loess areas.

Soil permeability under an in situ stress state can reflect water seepage in soil. There are more scholars who have performed a lot of research on loess. Li [1] studied the relationship between permeability and porosity in loess. The permeability coefficient is affected by dry density $[2,3]$, drywet cycle $[4,5]$, freeze-thaw cycles [6], confining pressure [4], structure [7, 8], and osmotic pressure [9]. The permeability coefficient function of remolded unsaturated loess was established under varying humidity and density [10].

Research on unsaturated soil permeability has yielded fruitful results. The seepage theory of unsaturated soils has been widely recognized in the field of geotechnical engineering [11]. Unsaturated soil permeability coefficient is an important parameter for studying water migration and distribution in soils. Methods for determining the 
permeability coefficient of unsaturated soils include the steady-state method [12] and the transient method [13, 14]. Because of the complexity and time-consuming nature of testing the permeability coefficient of unsaturated soils, the soil-water characteristic curve was commonly used to indirectly determine $k(\theta)[11,15]$. Some scholars used a linear model [16], van Genuchten-Mualem model [17], two-parameter power function model [18], empirical formula $[19,20]$, unsaturated hydraulic conductivity measurement system $[9,21]$, gaseous and liquid water migration model [22], or fractal geometry model [23] to study variations in permeability coefficient with matrix suction, saturation, volumetric water content, and effective saturation.

Research on permeability anisotropy primarily focused on clay, which focused on causes of permeability anisotropy [24], influencing factors [25], and permeability anisotropy models [26]. The permeability anisotropy ratio of clay increased with decreasing void ratio. With increasing consolidation stress, clay microparticles tend to be horizontal and permeability anisotropy increases $[4,27]$. Research on the permeability anisotropy of compacted loess, especially unsaturated compacted loess, is quite limited literature.

Examining the permeability anisotropy of compacted loess under the condition of water infiltration will have significant impacts on the distribution of water in filling foundations, embankments, filling slopes, water pipelines, and other engineering projects. This study describes an experimental study in which loess specimens with different dry densities are collected from different vertical and parallel compaction planes. Then, the saturated permeability coefficient $k_{\mathrm{sv}}$ in the direction of vertical compaction surface and $k_{\mathrm{sh}}$ in the direction of parallel compaction surface are determined using saturated permeability tests. The unsaturated permeability coefficients are calculated using the soil-water characteristic curves of unsaturated compacted loess with different dry densities. The equation between the unsaturated permeability anisotropy ratio and matrix suction is established by introducing the pore connectivity-tortuosity parameter. The microstructural characteristics of compacted loess were analyzed using scanning electron microscope (SEM) images to reveal the micromechanisms of permeability anisotropy of compacted loess in vertical and horizontal directions.

\section{Test Scheme}

2.1. Samples. Soil samples used in this study were $Q_{3}$ Malan loess collected from a foundation pit in Xi'an, China. Malan loess is yellowish brown, relatively weak, and wet. The physical properties of loess samples were determined following the Chinese National Standards (SAC 2019), which are shown in Table 1.

According to laboratory compaction tests following the Chinese National Standards [28], the optimal soil sample moisture content was $18.9 \%$, and the maximum dry density was $1.73 \mathrm{~g} / \mathrm{cm}^{3}$. Soil samples from the soil layer were naturally air-dried and then pulverized using a rubber hammer, which only separated the cemented particles but did not damage the loess particles. The pulverized loess was sieved through a $2 \mathrm{~mm}$ mesh in order to prepare soil samples with a water content of $18.9 \%$, which were sealed with plastic film for more than 48 hours to produce the desired water distribution and ensure the water content remains unchanged (Table 1). Samples were prepared using a specifically designed sample press. Wet soil was weighed based on the dry density and moisture content and was vertically compacted into five layers. Samples were $150 \mathrm{~mm}$ in diameter and $112 \mathrm{~mm}$ tall (Figure 1). The dry densities were $1.40 \mathrm{~g} /$ $\mathrm{cm}^{3}, 1.50 \mathrm{~g} / \mathrm{cm}^{3}, 1.60 \mathrm{~g} / \mathrm{cm}^{3}$, and $1.70 \mathrm{~g} / \mathrm{cm}^{3}$. The error was controlled to be $\leq 0.02 \mathrm{~g} / \mathrm{cm}^{3}$.

Soil samples were collected in the direction of vertical compaction surface (vertical samples) and parallel compaction surface (horizontal samples) (Figure 1). The permeability test samples were cut out using a soil cutting plate, and the samples were $39.1 \mathrm{~mm}$ in diameter and $80 \mathrm{~mm}$ high (Figure 1). Next, four vertical and four horizontal samples were put into a vacuum saturation device for saturation treatment until the saturation was greater than $95 \%$. Samples for the soil-water characteristic test were cut out of the compacted loess using a cutting ring with an inner diameter of $70 \mathrm{~mm}$ and a height of $19 \mathrm{~mm}$. The dry densities of the four samples were $1.40 \mathrm{~g} / \mathrm{cm}^{3}, 1.50 \mathrm{~g} / \mathrm{cm}^{3}, 1.60 \mathrm{~g} / \mathrm{cm}^{3}$, and $1.70 \mathrm{~g} / \mathrm{cm}^{3}$, respectively. Next, samples were put into a humidifying cylinder for sealing and moisturization. The samples for the scanning electron microscope (SEM) test were cut into $5 \mathrm{~mm} \times 5 \mathrm{~mm} \times 10 \mathrm{~mm}$ blocks with dry densities of $1.40 \mathrm{~g} / \mathrm{cm}^{3}, 1.50 \mathrm{~g} / \mathrm{cm}^{3}, 1.60 \mathrm{~g} / \mathrm{cm}^{3}$, and $1.70 \mathrm{~g} / \mathrm{cm}^{3}$. Four vertical and horizontal samples were used in the scanning electron microscope test.

\subsection{Testing Techniques}

2.2.1. Permeability Test and Result Analysis. The permeability test for saturated compacted loess used a SLB-1 triaxial permeameter apparatus (Figure 2). Samples were saturated using vacuum pumping and then put into the sample chamber to test the saturated permeability coefficient $k_{s}$ of the compacted loess samples with different dry densities. The test results of saturated permeability coefficients in vertical directions $\left(k_{s v}\right)$ and horizontal direction $\left(k_{s h}\right)$ are shown in Table 2.

The vertical and horizontal permeability coefficients of saturated compacted loess significantly decreased with the increase in dry density. That was because the dry density was smaller, the soil was dominated by macropores, the pore connectivity was better, and the permeability coefficient of saturated compacted loess was greater. On the contrary, the dry density was larger, the soil was dominated by micropores, the pore connectivity was poor, and the permeability coefficient of compacted loess was smaller (Table 2). The horizontal saturated permeability coefficient of compacted loess was larger than in the vertical direction, showing obvious anisotropy. Flake and needle particles were rotated to be parallel with the compaction surface after vertical compaction. The directionality of the particles, such as flake and needle, weakened the porosity and connectivity of the pores perpendicular to the compaction surface. On the 
TABle 1: Main indicator of the physical properties of loess.

\begin{tabular}{lcccccc}
\hline $\begin{array}{l}\text { Relative density } \\
G_{S}\end{array}$ & $\begin{array}{c}\text { Liquid limit } W_{L} \\
(\%)\end{array}$ & $\begin{array}{c}\text { Plastic limit } W_{P} \\
(\%)\end{array}$ & $\begin{array}{c}\text { Plasticity index } \\
I_{p}\end{array}$ & \multicolumn{3}{c}{ Particle composition (\%) } \\
\hline 2.72 & 30.8 & 18.6 & 12.2 & 3.72 & 52.18 & 15.44 \\
\hline
\end{tabular}
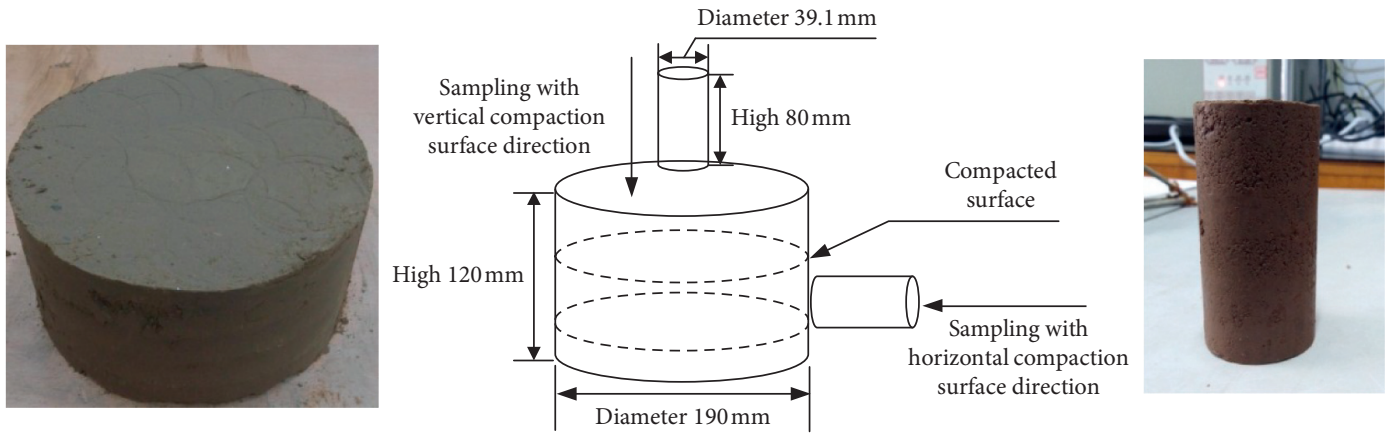

FIGURE 1: Samples of compacted loess and sampling direction.

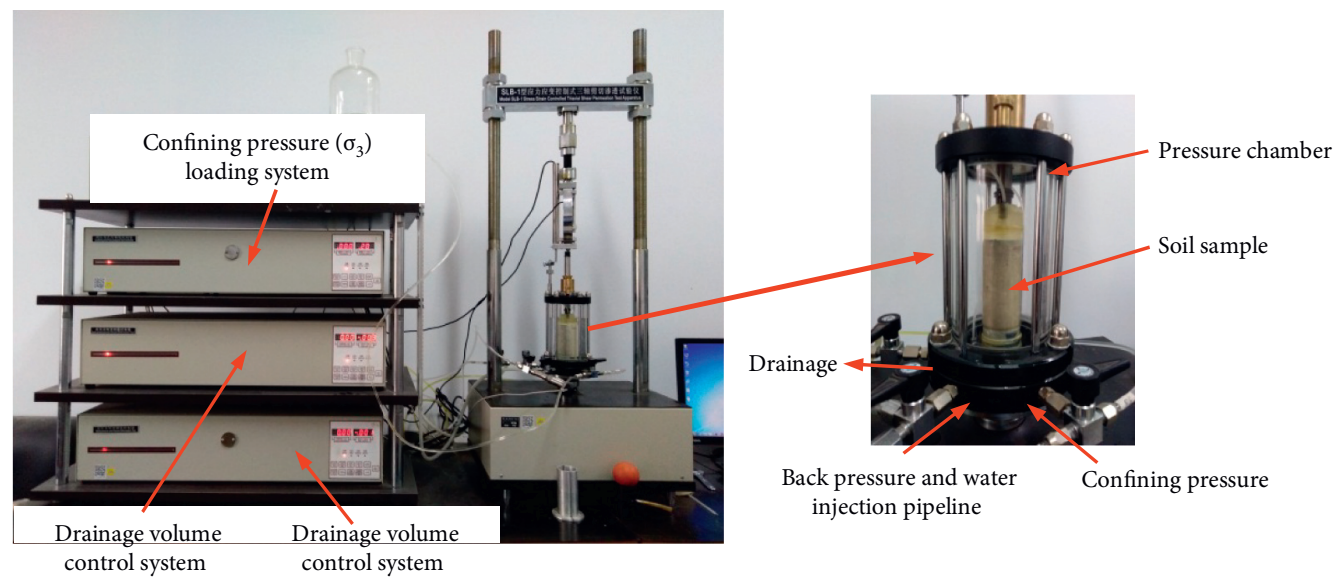

FIgURE 2: SLB-1 triaxial permeameter apparatus.

TABle 2: Permeability coefficient of saturated compacted loess.

\begin{tabular}{ccccccc}
\hline \multicolumn{2}{c}{$\rho_{d}=1.40 \mathrm{~g} / \mathrm{cm}^{3}$} & \multicolumn{2}{c}{$\rho_{d}=1.50 \mathrm{~g} / \mathrm{cm}^{3}$} & \multicolumn{2}{c}{$\rho_{d}=1.60 \mathrm{~g} / \mathrm{cm}^{3}$} & \multicolumn{2}{c}{$\rho_{d}=1.70 \mathrm{~g} / \mathrm{cm}^{3}$} \\
$k_{s v} / 10^{-6} \mathrm{~cm} / \mathrm{s}$ & $k_{s h} / 10^{-6} \mathrm{~cm} / \mathrm{s}$ & $k_{s v} / 10^{-6} \mathrm{~cm} / \mathrm{s}$ & $k_{s h} / 10^{-6} \mathrm{~cm} / \mathrm{s}$ & $k_{s v} / 10^{-6} \mathrm{~cm} / \mathrm{s}$ & $k_{s h} / 10^{-6} \mathrm{~cm} / \mathrm{s}$ & $k_{s v} / 10^{-6} \mathrm{~cm} / \mathrm{s}$ \\
\hline 87.769 & 109.030 & 24.213 & 5.848 & 9.625 & 16.083 & 3.205 \\
\hline
\end{tabular}

contrary, the porosity and connectivity of pores parallel to the compaction surface were improved. In addition, there are flaky clay minerals in the compacted loess. During the compaction process, the flaky clay minerals continuously rotate and finally parallel to the compacted surface. The increasing area of clay mineral particles blocked the connectivity of vertical pores, which ultimately led to a reduction in the vertical permeability coefficient [4].

2.2.2. Soil-Water Characteristic Curve Test. The soil-water characteristic curve test on unsaturated compacted loess used a soil-water characteristic curve pressure plate apparatus (Figure 3 ) and a high air entry ceramic plate (5 Bar). The high air entry ceramic plate has small pores of relatively uniform size. The plate acted as a membrane between air and water (Figure 4). Once the plate was saturated with water, air could not pass through the plate due to the ability of the contractile skin to resist airflow. The ability of the ceramic plate to withstand the airflow resulted from the surface tension of water, $T_{s}$, which acted like a thin membrane plugging the small pores of radius, $R_{s}$, on the surface of the ceramic plate. The difference between the air pressure above the contractile skin and the water pressure below the contractile skin was defined as matric suction. The maximum matric suction maintained across the surface of 


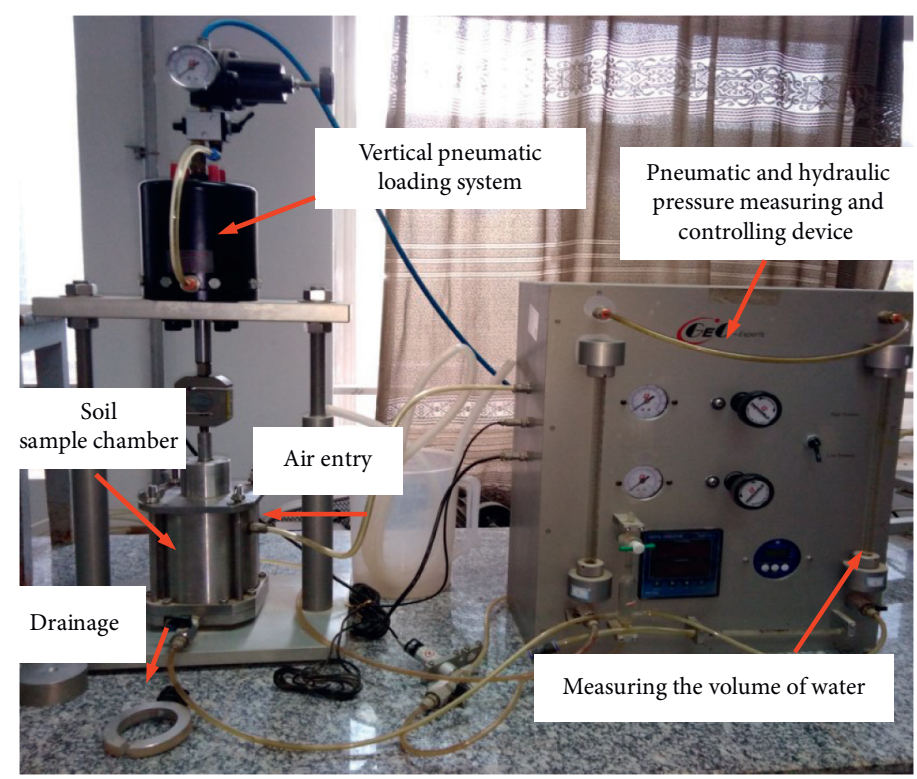

FIgURE 3: Soil-water characteristic curve pressure plate apparatus.

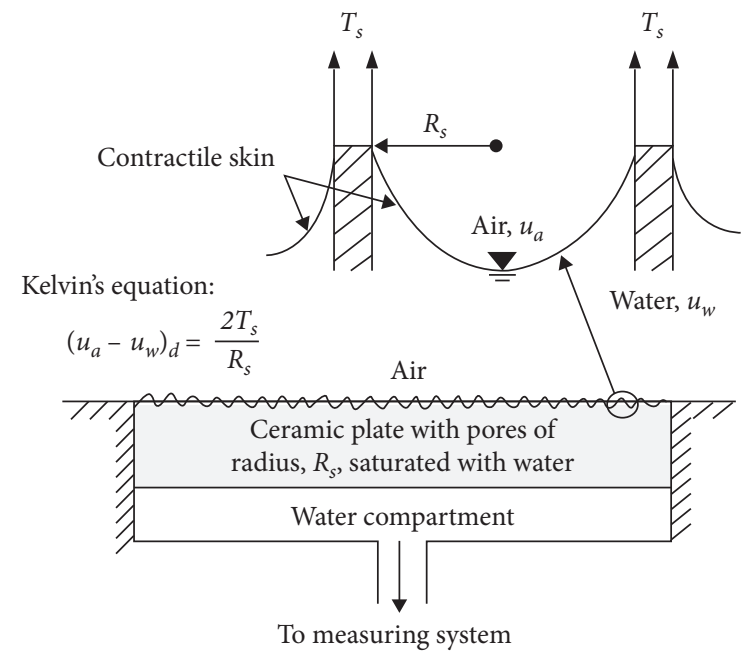

FIGURE 4: Operating principle of a high air entry plate as described by Kelvin's capillary model [11].

the plate is the air entry value, $\left(u_{g}-u_{w}\right) d[11]$. Each sample was tested at air pressures of $10 \mathrm{kPa}, 20 \mathrm{kPa}, 40 \mathrm{kPa}, 80 \mathrm{kPa}$, $100 \mathrm{kPa}, 140 \mathrm{kPa}$, and $180 \mathrm{kPa}$. Samples were saturated using vacuum with water. Then, the sample was put into the soil sample chamber, and air pressure was applied to the soil sample to measure the amount of water discharged from the sample. Measurements were recorded every $24 \mathrm{~h}$ for each air pressure level.

2.2.3. SEM Test. The samples for the scanning electron microscope (SEM) test were cut along the direction of vertical compaction surface and horizontal compaction surface for $5 \mathrm{~mm}$ in length, $5 \mathrm{~mm}$ in width, and $10 \mathrm{~mm}$ in height with the dry densities of $1.40 \mathrm{~g} / \mathrm{cm}^{3}, 1.50 \mathrm{~g} / \mathrm{cm}^{3}$, $1.60 \mathrm{~g} / \mathrm{cm}^{3}$, and $1.70 \mathrm{~g} / \mathrm{cm}^{3}$ (Figure 5). The samples were broken to be $5 \mathrm{~mm}$ in height and form a relatively flat and fresh section. The loose particles were blown off the surface. The surface was coated with a metal film. Then, the sample was put into the SEM to take 500-fold magnification SEM images.

\section{Permeability of Unsaturated Compacted Loess}

Water migration in unsaturated soils is significantly different from that in saturated soils. Water migration in unsaturated soils is primarily driven by matrix potential and gravity potential. Water migrates in liquid or gas and is affected by temperature, solute, and other complex conditions, making it difficult to accurately measure the permeability coefficient of unsaturated soil using a direct test. Permeability coefficients of saturated soils and soil-water characteristic curves of unsaturated soils are commonly used to indirectly determine permeability coefficients of unsaturated soils [29].

3.1. Soil-Water Characteristic Curve Test Results. The volumetric water content and matrix suction of compacted loess with dry densities of $1.40 \mathrm{~g} / \mathrm{cm}^{3}, 1.50 \mathrm{~g} / \mathrm{cm}^{3}, 1.60 \mathrm{~g} / \mathrm{cm}^{3}$, and $1.70 \mathrm{~g} / \mathrm{cm}^{3}$ are shown in Table 3 . With an increase in matrix suction, the volumetric water content of soil samples gradually decreased. When the soil dry density was high, the decrease in volumetric water content was smaller for the same change in matrix suction. On the contrary, when the dry density of soil was low, the decrease in volumetric water content was large for the same change in matrix suction (Table 3).

3.2. Determining $k(\theta)$ Using the Van Genuchten Soil-Water Characteristic Curve Model. Due to data complexity, data discreteness, and the time-consuming soil-water characteristic curve test, the test data represent only a part of 


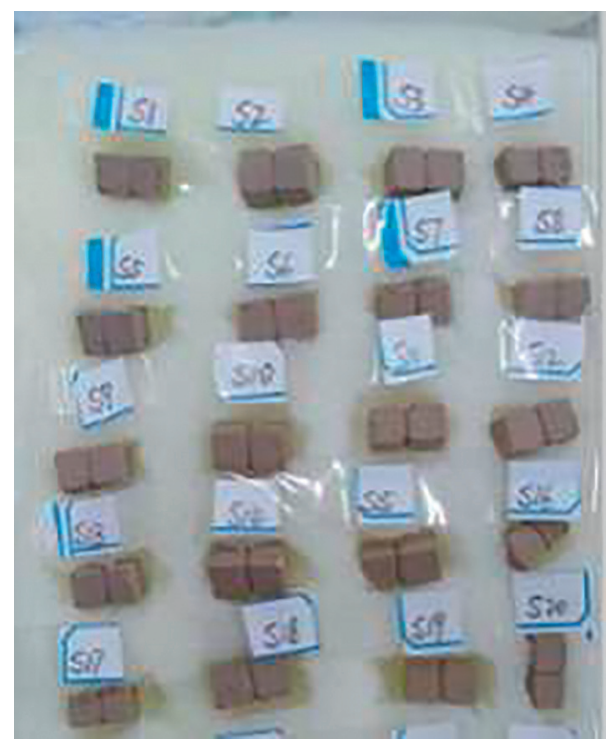

Figure 5: Samples of the scanning electron microscope test.

TABLE 3: Soil-water characteristic curve test values for compacted loess.

\begin{tabular}{|c|c|c|c|c|}
\hline \multirow{2}{*}{ Matric suction $\psi / \mathrm{kPa}$} & \multicolumn{4}{|c|}{ Volumetric water content $\theta / \%$} \\
\hline & $\rho_{d}=1.40 \mathrm{~g} / \mathrm{cm}^{3}$ & $\rho_{d}=1.50 \mathrm{~g} / \mathrm{cm}^{3}$ & $\rho_{d}=1.60 \mathrm{~g} / \mathrm{cm}^{3}$ & $\rho_{d}=1.70 \mathrm{~g} / \mathrm{cm}^{3}$ \\
\hline 0 & 46.76 & 43.65 & 40.48 & 37.40 \\
\hline 10 & 39.32 & 37.50 & 35.19 & 33.92 \\
\hline 20 & 33.21 & 32.18 & 31.87 & 30.76 \\
\hline 40 & 26.05 & 26.45 & 26.34 & 25.94 \\
\hline 60 & 22.10 & 22.43 & 23.18 & 23.42 \\
\hline 80 & 20.24 & 20.91 & 21.36 & 22.10 \\
\hline 100 & 19.13 & 19.86 & 20.30 & 21.36 \\
\hline 140 & 17.77 & 18.09 & 18.81 & 19.87 \\
\hline 180 & 16.96 & 17.27 & 17.89 & 18.79 \\
\hline
\end{tabular}

the soil-water characteristic curve. In order to obtain a complete soil-water characteristic curve, measured matrix suction and volume water content were fit using the van Genuchten model (1). The fitting parameters are shown in Table 4, and the fitting curves are shown in Figure 6. where $\psi$ represents matric suction $(\mathrm{kPa}) ; \theta$ represents volumetric moisture content $(\%) ; \theta_{s}$ represents saturated volumetric moisture content (\%); $\theta_{r}$ represents residual volumetric water content (\%); and $\alpha$ and $b$ represent model fitting parameters.

The expression of the van Genuchten model [29] is as follows:

$$
\frac{\theta-\theta_{r}}{\theta_{s}-\theta_{r}}=\left[1+(\alpha \psi)^{b}\right]^{1 / b-1} .
$$

Van Genuchten model equation correlates well with the fitting curve for the soil-water characteristic curve test data. Compacted loess with different dry densities had different matrix suctions due to different particle and pore structures. Matric suction at various dry densities increased with a decrease in volumetric water content (Figure 6). When matric suction increased to $40 \mathrm{kPa}$,
TABle 4: Fitting parameters of the van Genuchten model.

\begin{tabular}{lccccc}
\hline \multirow{2}{*}{ Dry density $\rho_{d} \cdot\left(\mathrm{g} / \mathrm{cm}^{3}\right)$} & \multicolumn{5}{c}{ Fitting parameters } \\
& $\theta_{s}(\%)$ & $\theta_{r}(\%)$ & $\alpha$ & $b$ & $R^{2}$ \\
\hline 1.40 & 46.76 & 11.8409 & 0.0818 & 1.7319 & 0.999 \\
1.50 & 43.65 & 10.8369 & 0.0794 & 1.6211 & 0.999 \\
1.60 & 40.48 & 9.6709 & 0.0743 & 1.5178 & 0.998 \\
1.70 & 37.40 & 13.7245 & 0.0634 & 1.6202 & 0.999 \\
\hline
\end{tabular}

because of the water holding capacity of large and small pores in different dry densities was exactly the same, the soil-water characteristic curves intersect at a point where the volumetric water content was approximately equal. For the same volume of water, when $\psi<40 \mathrm{kPa}$, the dry density decreased, and the matrix suction increased. When matrix suction was low, pores in smaller dry density soils were larger, and water capacity decreased. When $\psi>40 \mathrm{kPa}$, the dry density and matrix suction increased due to the increased number of small pores in higher dry density soil. Matrix suction was larger in small pores compared to large pores (Table 4).

The soil-water characteristic curve (Figure 6) was divided into $m$ equal parts along the volumetric water content axis, 


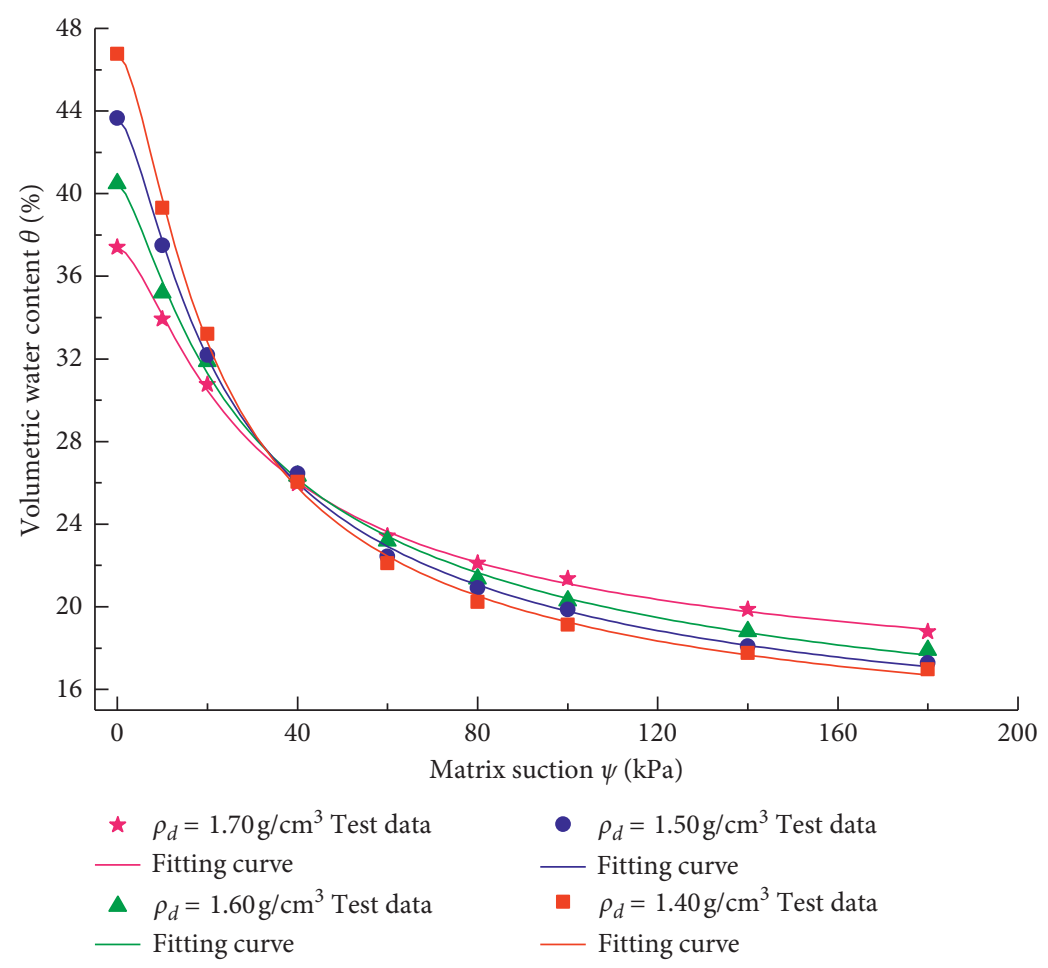

Figure 6: Soil-water characteristic curve fit using the van Genuchten model.

and the matrix suction corresponding to each section midpoint was obtained. According to the Childs and CollisGeroge model [30], the permeability coefficient $k(\theta)$ of unsaturated compacted loess is given by

$$
\begin{aligned}
k(\theta)_{i} & =\frac{k_{s}}{k_{s c}} A_{d} \sum_{j=i}^{m}\left[(2 j+1-2 i)\left(u_{a}-u_{w}\right)_{j}^{-2}\right], \quad i=1,2, \cdots, m, \\
k_{s c} & =A_{d} \sum_{j=i}^{m}\left[(2 j+1-2 i)\left(u_{a}-u_{w}\right)_{j}^{-2}\right], \quad i=0, \\
A_{d} & =\frac{T_{s}^{2} \rho_{w} g \theta_{s}^{p}}{2 \mu_{w} N^{2}},
\end{aligned}
$$

where $k(\theta)_{i}$ represents permeability coefficient corresponding to volume moisture content $\theta_{i}(\mathrm{~cm} / \mathrm{s}) ; k_{s}$ represents saturated permeability coefficient measured by experiment $(\mathrm{cm} / \mathrm{s}) ; k_{s c}$ represents calculative saturated permeability coefficient $(\mathrm{cm} /$ s); $A_{d}$ represents an adjustment constant, which is related to the density and surface tension of water; $T_{s}$ represents water surface tension $(\mathrm{kN} / \mathrm{m}) ; p_{w}$ represents water density $\left(\mathrm{kg} / \mathrm{m}^{3}\right)$; $g$ represents gravity acceleration $\left(\mathrm{m} / \mathrm{s}^{2}\right) ; \mu_{w}$ represents water absolute viscosity $\left(N \cdot \mathrm{s} / \mathrm{m}^{2}\right) ; \theta_{s}$ represents saturated volumetric water content (\%); $\left(u_{g}-u_{w}\right) d$ represents matrix suction corresponding to the middle point of $j$ interval $(\mathrm{kPa})$; $m$ represents equivalent fraction between saturated volumetric water content and minimum volumetric water content on the soil-water characteristic curve $(m=10) ; i$ represents discontinuous numbering; and $j$ represents counting from $i$ to $m$.

Matrix suction did not show anisotropy, so the horizontal and vertical suctions were equal. Based on the saturated permeability coefficients $k_{s}$ measured in the vertical and horizontal directions based on the permeability test at $\left(u_{g}-u_{w}\right)=0 k P a$ (Table 2) combined with the matrix suction $\left(u_{g}-u_{w}\right) i$, equations (2)-(4), the unsaturated permeability coefficients $k_{v}$ in the vertical direction and $k_{h}$ parallel compaction plane of compacted loess were calculated, respectively (Table 5). In order to study the influence of matrix suction on permeability coefficient of unsaturated compacted loess, the curves between permeability coefficient and matrix suction of unsaturated compacted loess with different dry densities were determined (Figure 7).

The permeability coefficient of unsaturated compacted loess was significantly affected by matrix suction and decreased with an increase in matrix suction. When matrix suction was less than $10 \mathrm{kPa}$, the relationship between permeability coefficient in the horizontal and vertical directions and the matrix suction sharply decreased. When matrix suction was greater than $10 \mathrm{kPa}$ and less than $40 \mathrm{kPa}$, the slope of the relationship curve gradually decreased and tended to be gentle. When the matrix suction was greater than $40 \mathrm{kPa}$, the difference between the vertical and horizontal permeability coefficients was less than $0.01 \times 10^{-6} \mathrm{~cm} / \mathrm{s}$, and the relationship curve tended to be consistent.

3.3. Permeability Anisotropy of Unsaturated Compacted Loess. The influence of pore connectivity and tortuosity on water flow in pores in different directions was different from saturated soils [31]. Matrix suction had a significant effect on unsaturated permeability anisotropy of layered soils 


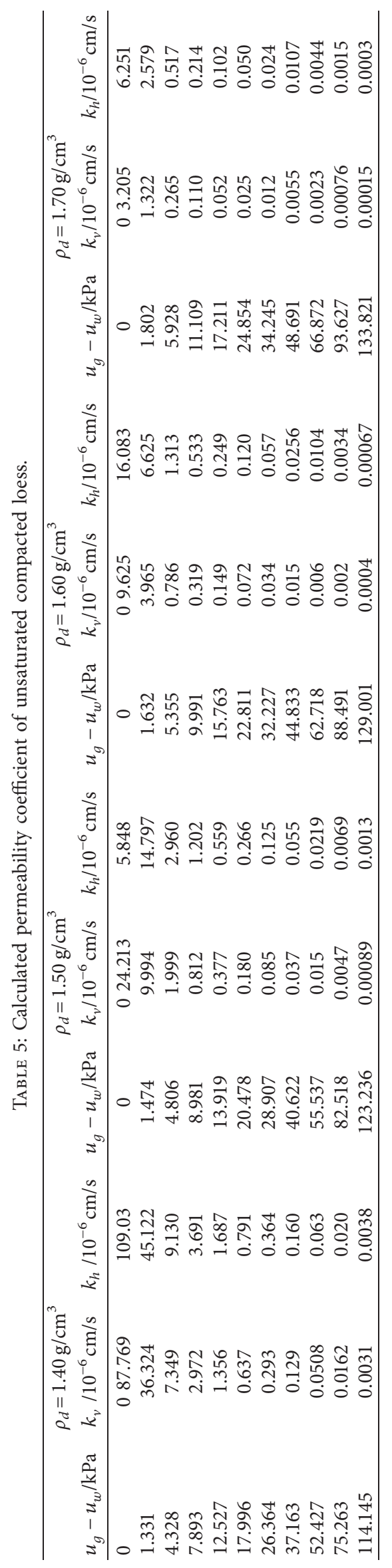




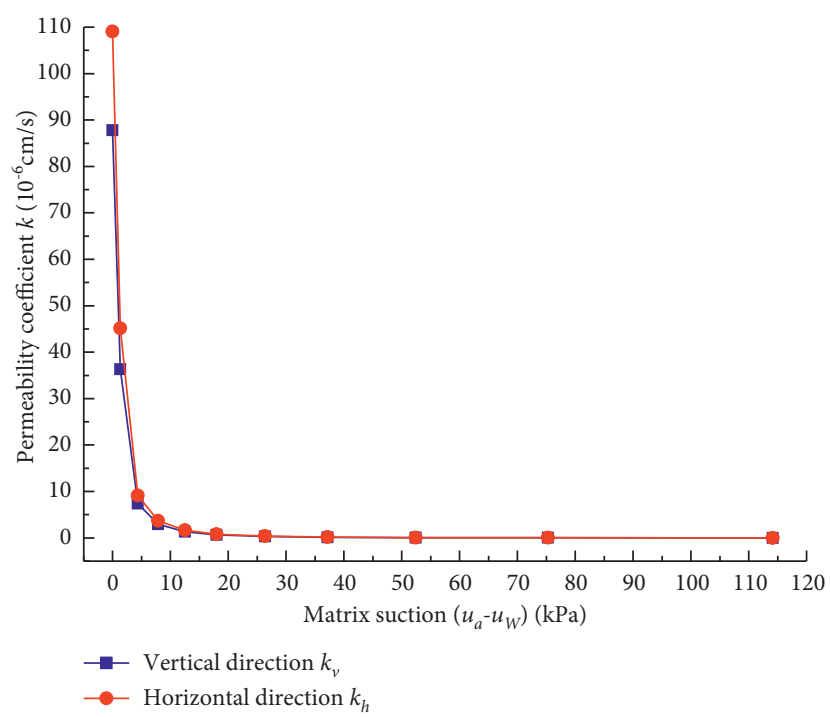

(a)

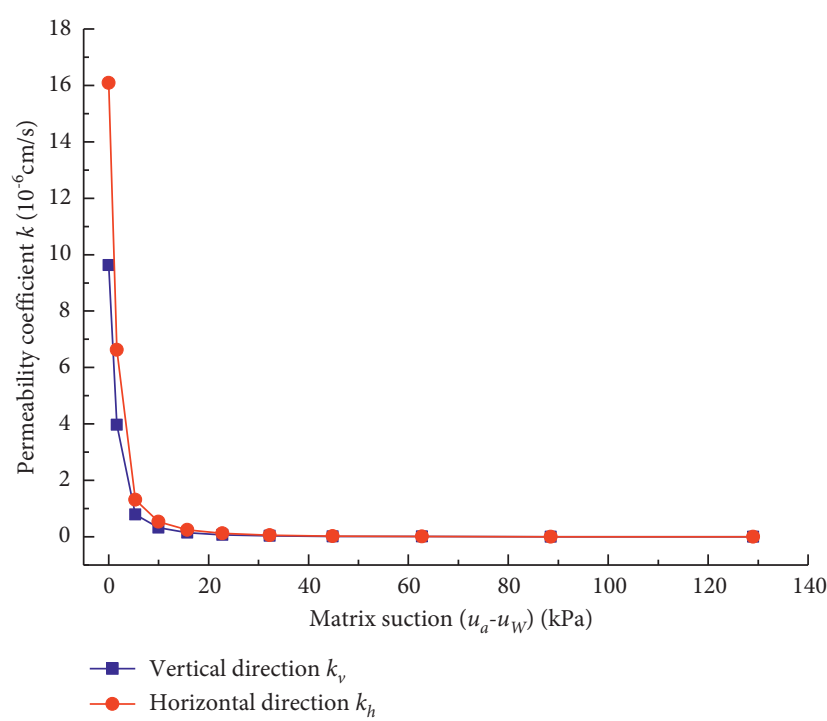

(c)

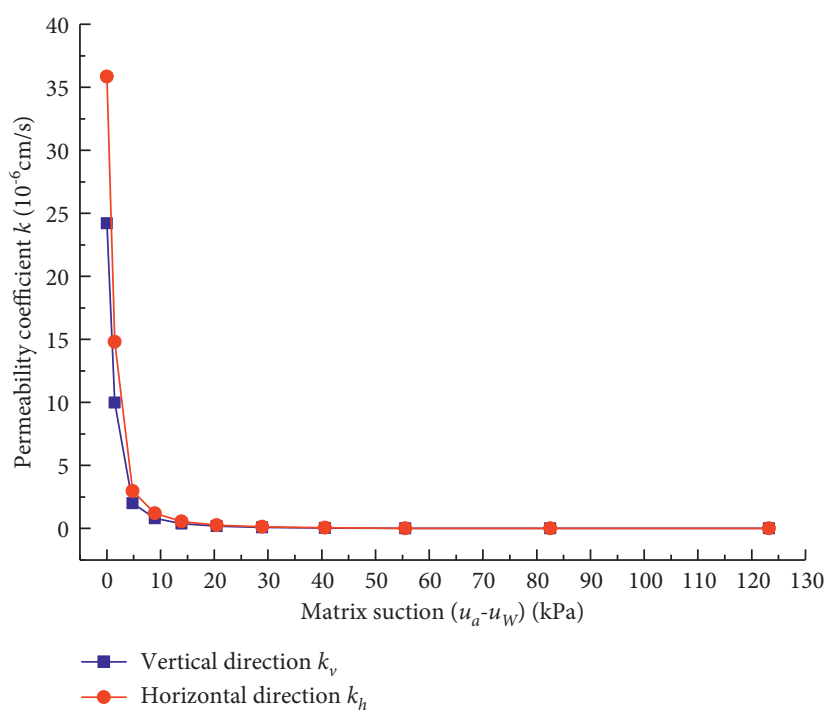

(b)

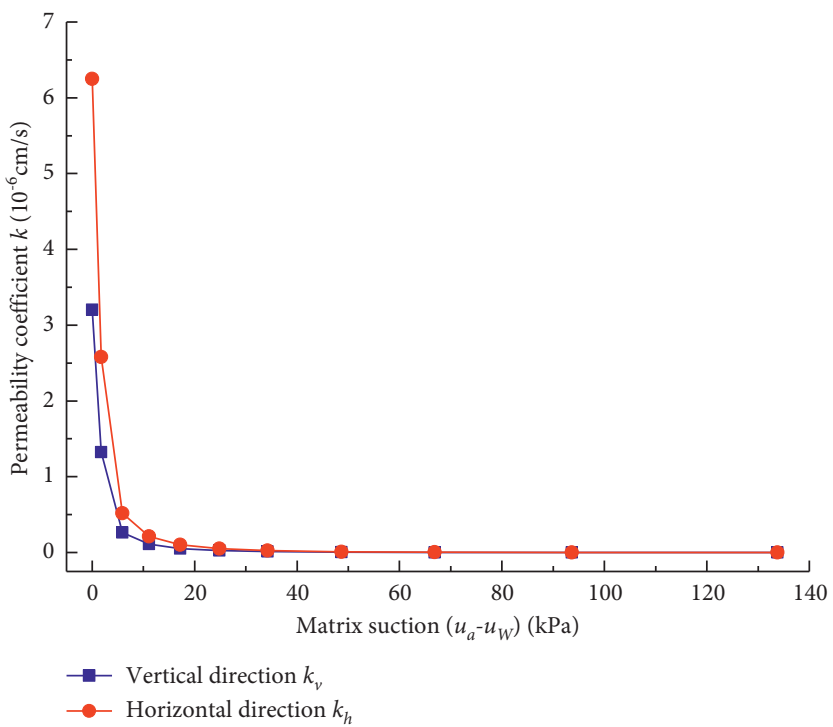

(d)

Figure 7: Relationship between permeability coefficient and matrix suction of unsaturated compacted loess: (a) $\rho_{d}=1.40 \mathrm{~g} / \mathrm{cm}^{3},(\mathrm{~b})$ $\rho_{d}=1.50 \mathrm{~g} / \mathrm{cm}^{3}$, (c) $\rho_{d}=1.60 \mathrm{~g} / \mathrm{cm}^{3}$, and (d) $\rho_{d}=1.70 \mathrm{~g} / \mathrm{cm}^{3}$.

[32]. The theoretical relationship between anisotropy and saturation was put forward by Mualem [33]. Saturated permeability anisotropy is closely related to the degree of soil saturation [33]. The permeability coefficient of unsaturated soils indirectly calculated using the soil-water characteristic curve was based on the saturated permeability coefficient. The anisotropy of the unsaturated permeability coefficient perpendicular and parallel to the compaction plane was consistent with the saturated permeability anisotropy, which could not show that unsaturated permeability anisotropy was affected by matrix suction.

Pore connectivity-tortuosity parameter $L$ was introduced to study the unsaturated permeability coefficient of isotropic soils [33].

$$
\begin{aligned}
k & =C k_{s}\left(S_{e}\right)^{L}, \\
C & =\left\{\frac{\int_{0}^{S_{e}}[\psi(x)]^{-1} \mathrm{~d} x}{\int_{0}^{1}[\psi(x)]^{-1} \mathrm{~d} x}\right\}^{2}, \\
S_{e} & =\frac{\theta-\theta_{r}}{\theta_{s}-\theta_{r}},
\end{aligned}
$$

where $k$ represents permeability coefficient $(\mathrm{cm} / \mathrm{s}) ; S_{e}$ represents effective degree of saturation (\%); $L$ represents pore connectivity-tortuous parameters; $\psi$ represents matric suction $(\mathrm{kPa}) ; \theta$ represents volumetric moisture content $(\%)$; $\theta_{s}$ represents saturated volumetric moisture content (\%); and $\theta_{r}$ represents residual volumetric water content (\%). 
Based on the unsaturated permeability coefficient function proposed by Mualem [17], Zhang et al. [34] introduced a pore connectivity-tortuosity parameter $L$ to establish the relationship between unsaturated permeability coefficient, saturated permeability coefficient, and matrix suction (van Genuchten-Mualem equation).

$$
k=k_{s}\left[1+(\alpha \psi)^{b}\right]^{L(1 / b-1)}\left\{1-\left[\frac{(\alpha \psi)^{b}}{1+(\alpha \psi)^{b}}\right]^{1-1 / b}\right\}^{2}
$$

$A_{h v}=\left(\frac{k_{s h}}{k_{s v}}\right) \cdot\left[1+(\alpha \psi)^{b}\right]^{\Delta L_{h v} \cdot(1 / b-1)}$,

where $A_{h v}$ represents anisotropy coefficient; $\Delta L_{h y}=L_{h}-L_{v}$ represents pore connectivity-tortuous parameters for horizontal direction, and $L_{v}$ represents pore connectivity-tortuous parameters for the vertical direction.

Pore connectivity-tortuosity parameters were obtained by fitting the measured unsaturated permeability coefficient into equation (6). Fitted parameters were substituted into equation (7) to analyze the anisotropy of unsaturated permeability coefficient; however, the physical meaning, which reflected the pore connectivity and tortuosity of compacted loess, was not clear. The permeability of water in soil was influenced by pore characteristics and was determined by the connectivity-tortuosity of pores under a certain hydraulic gradient. Permeability coefficient was an intuitive expression of pore connectivity-tortuosity. The difference in horizontal and vertical permeability coefficients for saturated compacted loess directly reflected differences in pore connectivity-tortuosity characteristics in the vertical and horizontal directions. The saturated permeability anisotropy ratio not only reflected differences in horizontal and vertical permeability coefficients for saturated compacted loess but also reflected differences in connectivity-tortuosity characteristics of soil pores. If the common pore characteristics reflected in the saturated permeability anisotropy ratio $r_{k s}$ were removed, then the difference between the horizontal and vertical pore connectivity-tortuosity characteristics (pore connectivity-tortuosity parameter $L$ ) in compacted loess could be obtained. The saturated permeability anisotropy ratio was used to represent pore connectivity-tortuosity parameters, and its physical meaning was clear.

According to the definition of permeability anisotropy ratio for saturated compacted loess, unsaturated permeability anisotropy was defined as the ratio $r_{k}$. The permeability anisotropy of unsaturated compacted loess was expressed using the saturated permeability anisotropy ratio, and the pore connectivity-tortuosity parameter was introduced to establish the relationship between the unsaturated permeability anisotropy ratio and effective saturation degree.

$$
r_{k}=r_{k s} \cdot\left(S_{e}\right)^{L}
$$

Equations (1) and (5) are substituted into equation (8):

$$
r_{k}=r_{k s} \cdot\left[1+(\alpha \psi)^{b}\right]^{L \cdot(1 / b-1)},
$$

where $r_{k}$ represents anisotropic ratio of unsaturated permeability; $r_{k s}$ represents anisotropic ratio of saturated permeability; and $L$ represents pore connectivity-tortuous parameters, when $r_{k s}>1, L=r_{k s}-1$, and when $r_{k s}<1, L=-r_{k s}-1$.

For saturated soil, the matrix suction is $\psi=0 \mathrm{kPa}$, and when the soil was isotropic, $r_{k s}=1, L=0$, and then, $r_{k}=1$.

According to equation (9) in combination with data from Tables 1 and 5, the curve between permeability anisotropy ratio and matrix suction of unsaturated compacted loess was calculated (Figure 8):

(1) The permeability anisotropy of unsaturated compacted loess decreased with an increase in matrix suction. The pore connectivity-tortuosity parameter clearly reflects the influence of matrix suction on the permeability anisotropy of unsaturated compacted loess.

(2) When $\rho_{d}=1.7 \mathrm{~g} / \mathrm{cm}^{3}$, the difference in pore structure and particle arrangement in the horizontal and vertical directions during loess compaction increased, and the difference in pore connectivity and tortuous path in the horizontal and vertical directions was more significant, as shown by the larger pore connectivity-tortuous parameter values. The anisotropy ratio of unsaturated permeability was significantly affected by matrix suction, and the curve was steeper. When $\rho_{d}=1.4 \mathrm{~g} / \mathrm{cm}^{3}$, the difference in pore structure and particle arrangement in the horizontal and vertical directions during the loess compaction process was smaller, and the difference in pore connectivity and tortuous path in the horizontal and vertical directions decreased, as shown by the smaller pore connectivity-tortuous parameter values. The anisotropy ratio of unsaturated permeability was less affected by matrix suction, and the curve was gentle.

(3) Pore connectivity-tortuous parameters not only reflect the influence of matrix suction on permeability anisotropy of unsaturated compacted loess but also reflect the pore structure and arrangement characteristics of compacted loess with different dry densities, which is of great significance to the study of water migration in unsaturated compacted loess.

3.4. Rationality Verification of Defined Pore Connectivity-Torture Parameter. Zhang et al. [34] used equations (6) and (7) to analyze the influence of matrix suction on the anisotropy coefficient of three types of soils: Cass sandy loam, Fort Collins clay loam [35], and Xi'an $Q_{3}$ undisturbed loess [36]. In this study, the unsaturated permeability anisotropy of the above three soils was analyzed using equation (9). Results were compared with the results of Zhang et al. [34], in order to verify the rationality of the proposed pore connectivitytortuosity parameter and equation (9) (Figure 9).

Compared with the results of equation (7), the unsaturated permeability anisotropy for the three soil types calculated using equation (9) was in good agreement with the test data (Figure 9). The relative error between the test data 


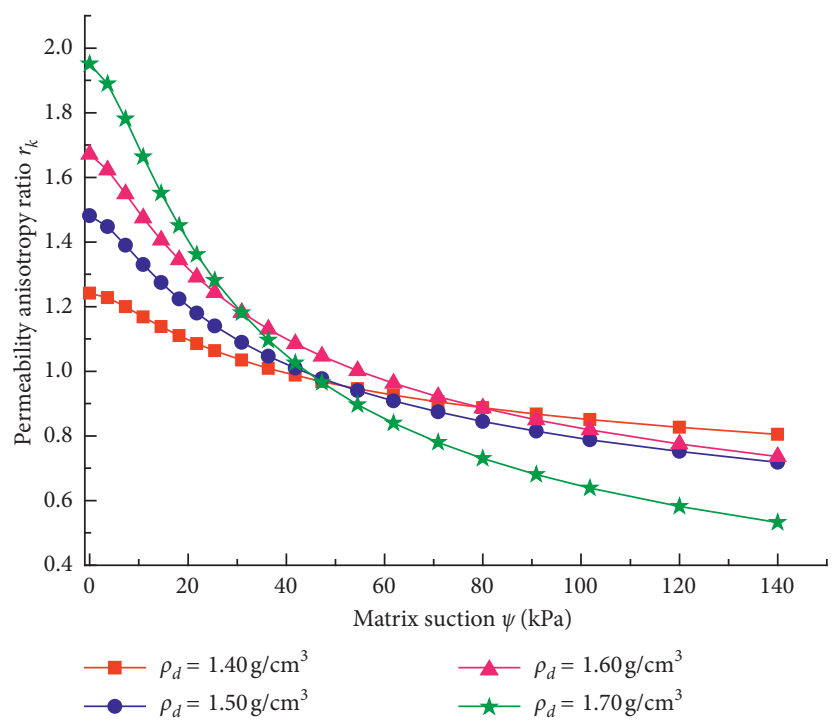

FIGURE 8: Relationship between permeability anisotropy ratio and matrix suction.

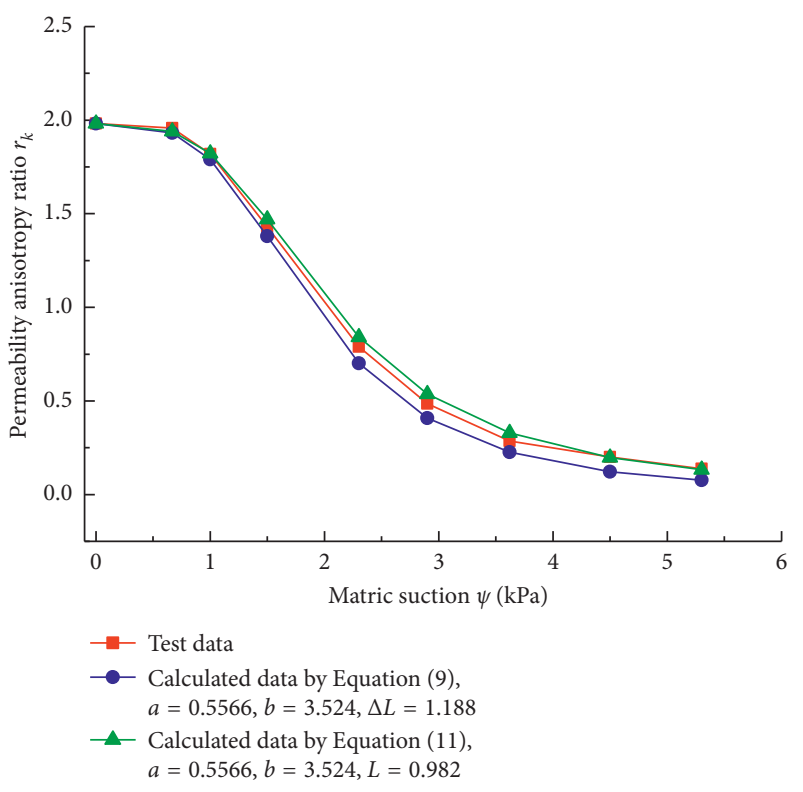

(a)

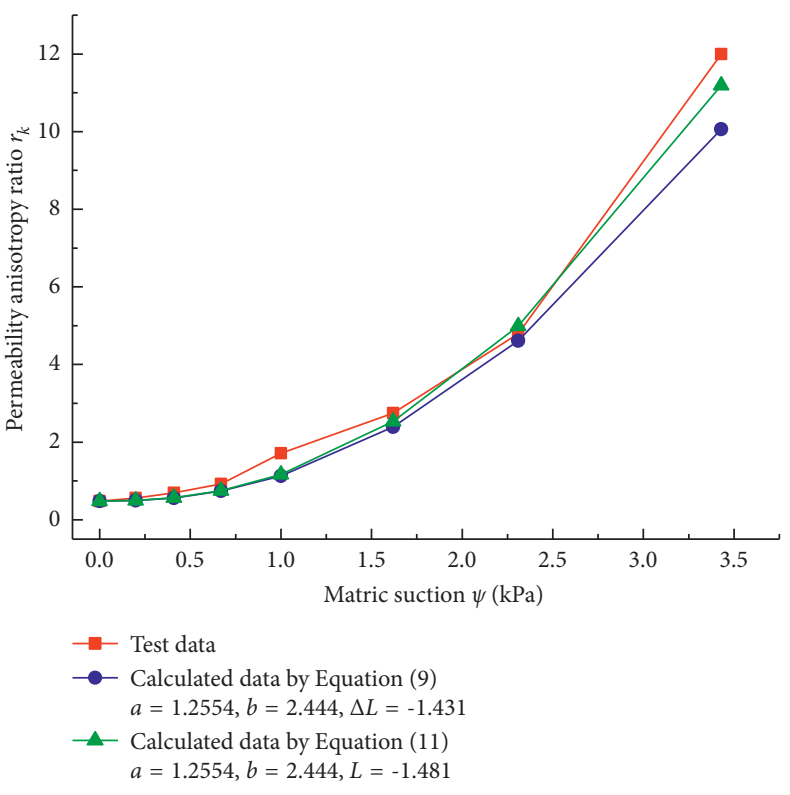

(b)

Figure 9: Continued. 


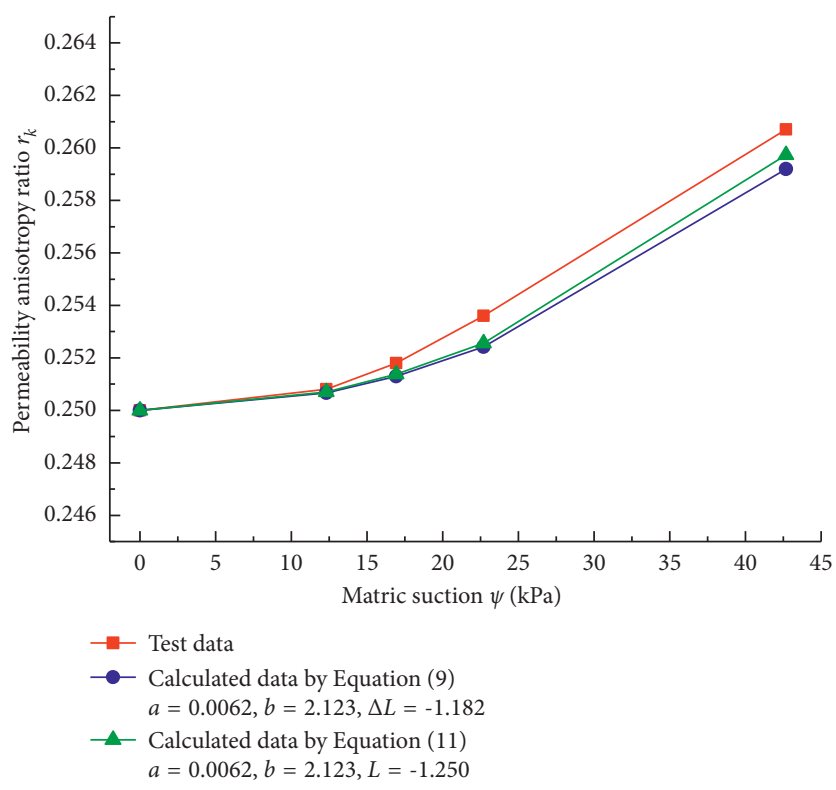

(c)

FIGURE 9: Relationship between measured and calculated unsaturated permeability anisotropy ratio and matrix suction for three types of soils. (a) Cass sandy loam [35], (b) Fort Collins clay loam [35], and (c) Xi'an $Q_{3}$ undisturbed loess [36].

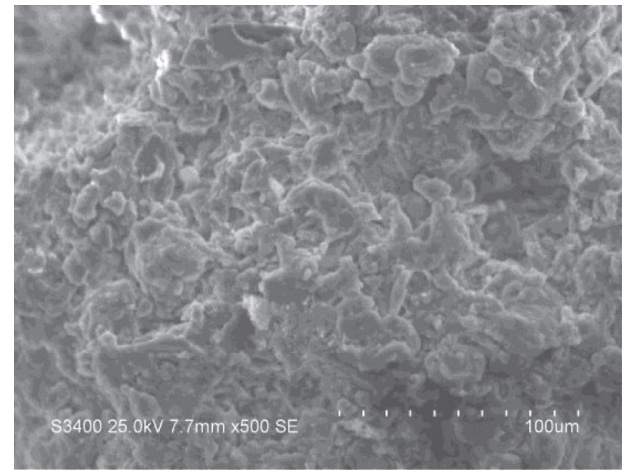

SEM image on compacted surface

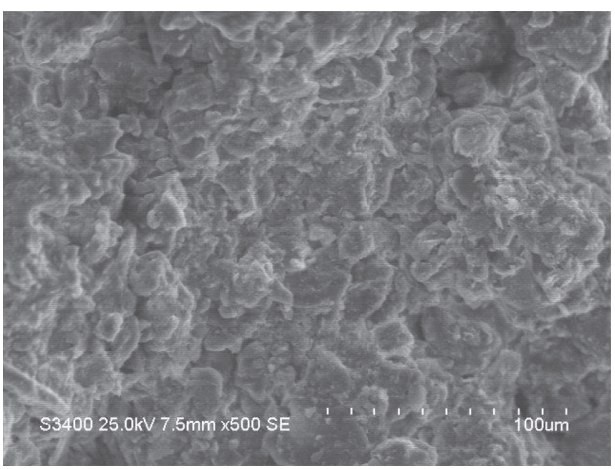

SEM image on compacted surface

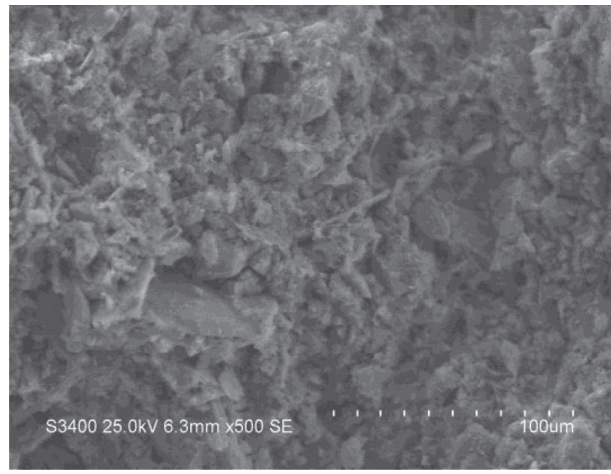

SEM image on vertical compacted surface

(a)

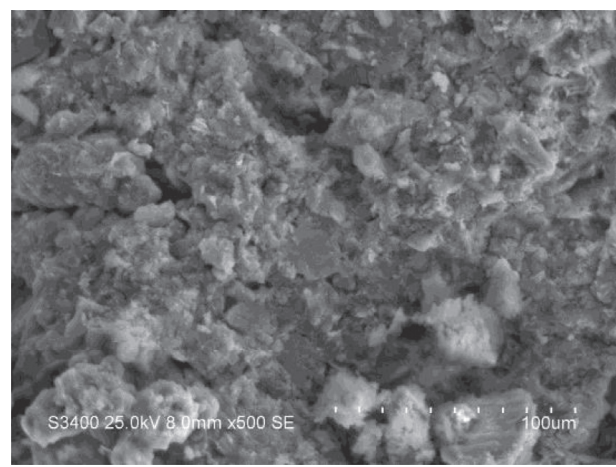

SEM image on vertical compacted surface

(b)

Figure 10: Continued. 


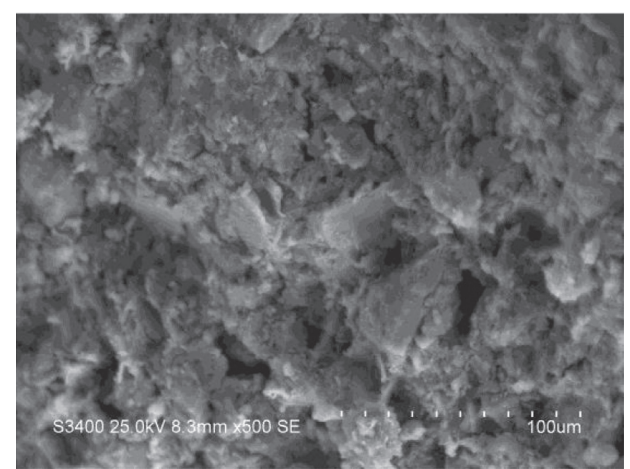

SEM image on compacted surface

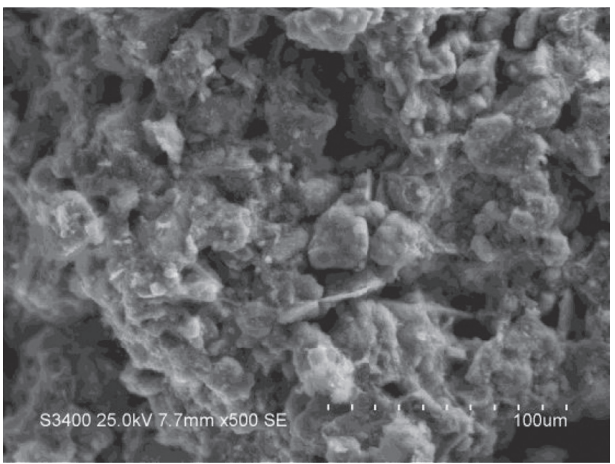

SEM image on compacted surface

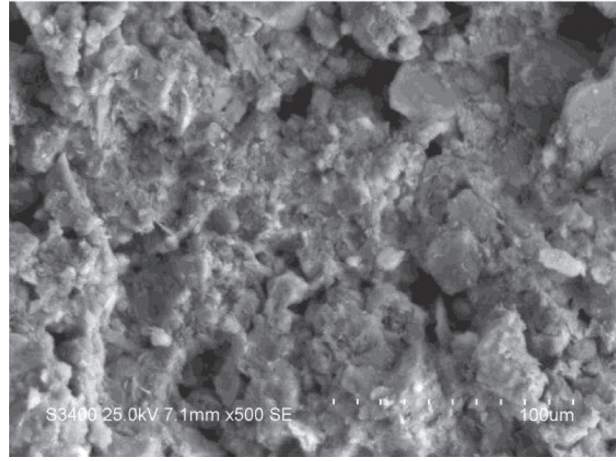

SEM image on vertical compacted surface

(c)

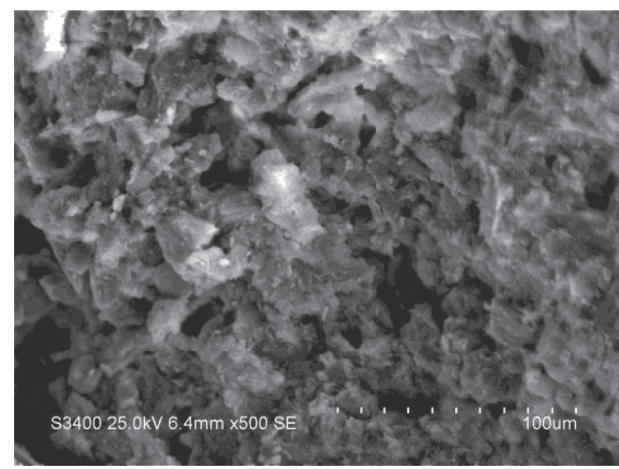

SEM image on vertical compacted surface

(d)

Figure 10: SEM images with different dry densities $(500$ times $)[4] .(\mathrm{a}) \rho_{\mathrm{d}}=1.70 \mathrm{~g} / \mathrm{cm}^{3},(\mathrm{~b}) \rho_{\mathrm{d}}=1.60 \mathrm{~g} / \mathrm{cm}^{3},(\mathrm{c}) \rho_{\mathrm{d}}=1.50 \mathrm{~g} / \mathrm{cm}^{3}$, and (d) $\rho_{\mathrm{d}}=1.40 \mathrm{~g} / \mathrm{cm}^{3}$.

and the calculated data using equation (7) was $16.4 \%-23.2 \%$, and the relative error between the test data and the calculated data using equation (9) was $4.1 \%-8.7 \%$. Thus, the pore connectivity-tortuosity parameters defined in this contribution can reasonably describe the variation in permeability anisotropy of unsaturated soils with matrix suction.

\section{Microscopic Mechanism of Permeability Anisotropy}

SEM tests were carried out on loess samples with different compacted dry densities to obtain images, which are shown in Figure 10.

The micropore structures of the compacted surface and vertical compacted surface were significantly different (Figure 10). The number of pores perpendicular to the compacted surface was greater than that of the compacted surface, and pore connectivity was better. This was the primary reason why the permeability coefficient of compacted loess was large parallel to the compacted surface was larger compared to the permeability perpendicular to the compacted surface. The number of pores on the compacted surface and perpendicular to the compacted surface gradually increased with a decrease in dry density. However, the difference of pore diameter and number on the compacted surface and perpendicular to the compacted surface decreased with a decrease in dry density, which revealed the reason why smaller dry densities correlate with smaller permeability anisotropy. On the contrary, when the dry density was higher, the permeability anisotropy was greater [4].

\section{Conclusions}

By conducting permeability test and soil-water characteristic curve test on compacted loess of different dry densities, this study investigated the permeability anisotropy of unsaturated compacted loess and drew the following conclusions:

(1) The vertical and horizontal permeability coefficients of saturated compacted loess significantly decreased with the increase in dry density. The horizontal saturated permeability coefficient of compacted loess was larger than that in the vertical direction, showing obvious anisotropy. Flake and needle particles rotated to be parallel with the compaction surface after vertical compaction, which weakened the porosity and connectivity of the pores, led to a reduction in vertical saturated permeability coefficient. The porosity and connectivity of pores parallel to the compaction surface were improved to make the horizontal permeability coefficient larger. 
(2) Van Genuchten model equation correlated well with the fitting curve for the soil-water characteristic curve test data. Based on the vertical and horizontal saturated permeability coefficients, the permeability coefficient of unsaturated compacted loess was calculated using the soil-water characteristic curve fitted using the van Genuchten model and Childs and Collis-Geroge model. The permeability anisotropy of unsaturated compacted loess could be expressed by the ratio of unsaturated permeability anisotropy.

(3) The pore connectivity-tortuosity parameter was introduced to establish the equation between the unsaturated permeability anisotropy ratio and matrix suction. The rationality of the equation was verified by comparing test and calculated datasets for unsaturated permeability anisotropy of Cass sandy loam, Fort Collins clay loam, and Xi'an $Q_{3}$ undisturbed loess. The physical meaning of the introduced pore connectivity-tortuosity parameter was clear and reasonable, and the pore connectivity-tortuosity parameter could express the relationship between the anisotropy ratio of unsaturated permeability and matrix suction.

(4) The microtest showed that the permeability anisotropy of compacted loess with different dry density was mainly caused by the different pore structures in the direction of vertical compaction surface and horizontal compaction surface [37].

\section{Abbreviations}

$\mathrm{Q}_{3}: \quad$ Late Pleistocene epoch

$G_{S}$ : $\quad$ Specific gravity of soil particle

$\rho_{d}: \quad$ Dry density

$W_{L}: \quad$ Liquid limit

$W_{P}: \quad$ Plastic limit

$I_{p}: \quad$ Plasticity index

SEM: $\quad$ Scanning electron microscope

$k: \quad$ Permeability coefficient

$k_{s}$ : $\quad$ Saturated permeability coefficient

$k_{s h}$ : Horizontal saturated permeability coefficient

$k_{s h}$ : $\quad$ Vertical permeability coefficient

$r_{k s}: \quad$ Saturated permeability anisotropy ratio

$\psi: \quad$ Matric suction

$\theta: \quad$ Volumetric moisture content

$\theta_{s}: \quad$ Saturated volumetric moisture content

$\theta_{r}: \quad$ Residual volumetric water content

$\alpha$ and Model fitting parameters

$b$ :

$k(\theta)_{i}$ : Permeability coefficient corresponding to volume moisture content $\theta_{i}$

$k_{s c}: \quad$ Calculative saturated permeability coefficient

$A_{d}: \quad$ Adjustment constant

$T_{s}$ : Water surface tension

$\rho_{w}: \quad$ Water density

g: $\quad$ Gravity acceleration

$\mu \mathrm{w}$ : Water absolute viscosity $\left(u_{a}-u_{w}\right)$ Matrix suction corresponding to the middle point $j$ : $\quad$ of $j$ interval

$m$ : $\quad$ Equivalent fractions between saturated volumetric water content and minimum volumetric water content on soil-water characteristic curve

$i$ : Discontinuous numbering

$j$ : $\quad$ Counting from $i$ to $m$

$S_{e}: \quad$ Effective degree of saturation

$L$ : $\quad$ Pore connectivity-tortuous parameters

$A_{h v}: \quad$ Anisotropy coefficient

$L_{h}$ : $\quad$ Pore connectivity-tortuous parameters for horizontal direction

Lv: Pore connectivity-tortuous parameters for vertical direction

$r_{k}$ : Anisotropic ratio of unsaturated permeability.

\section{Data Availability}

The data used to support the findings of this study are available from the corresponding author upon request.

\section{Conflicts of Interest}

The authors declare no conflicts of interest in connection with the work submitted.

\section{Acknowledgments}

This study was supported by the Key Research and Development Program of Shaanxi, China. The authors would like to thank the team workers of the Geotechnical Engineering Laboratory at the Henan University of Urban Construction. This work was supported by the Key Research and Development Program of Shaanxi, China (program no. 2018ZDCXL-SF-30-9).

\section{References}

[1] Y. F. Li, "Relationship between the permeability and the porosity of Luochuan loess layer," Chinese Journal of Xi'an College of Geology, vol. 13, no. 2, pp. 60-64, 1991.

[2] T. H. Wang, J. Lu, and J. F. Zhang, "Experimental study of permeability coefficient of artificially compacted unsaturated loess considering influence of density," Chinese Journal of Rock Mechanics and Engineering, vol. 25, no. 11, pp. 2364-2368, 2006.

[3] H. Wang, Z. R. Yue, and C. L. Ye, "Experimental investigation of permeability characteristics of intact and reshaped loess," Chinese Journal of Shijiazhuang Railway Institute (Natural Science), vol. 22, no. 2, pp. 20-22, 2009.

[4] Y. Z. Hao, T. H. Wang, L. Cheng, and J. L. Li, "Experimental study on the saturated compacted loess permeability under $K_{0}$ consolidation," Advances in Civil Engineering, vol. 2020, Article ID 1426485, 2020.

[5] K. Z. Yuan, W. K. Ni, X. F. Lu, and X. J. Wang, "Permeability characteristics and structural evolution of compacted loess under different dry densities and wetting-drying cycles," PLoS One, vol. 16, no. 6, Article ID e0253508, 2021.

[6] J. Lu, T. H. Wang, W. C. Cheng, T. Yang, and Y. Luo, "Permeability anisotropy of loess under influence of dry 
density and freeze-thaw cycles," International Journal of Geomechanics, vol. 19, no. 9, Article ID 04019103, 2019.

[7] Y. Chen, H. Qian, K. Hou, Q. Zhang, and Y. Zhang, "Permeability and paleoenvironmental implications of loess-paleosol sequence from Jingyang Loess Plateau," Environmental Earth Sciences, vol. 80, no. 18, 2021.

[8] Y. Z. Hao, T. H. Wang, and J. J. Wang, "Structural properties of unsaturated compacted loess for various sample moisture contents," Arabian Journal of Geosciences, vol. 12, no. 8, pp. 258-268, 2019.

[9] Y. X. Zhao, H. Y. Zhang, Q. F. Lu, and X. B. Liang, "Experimental study of unsaturated permeability coefficient of compacted loess," Rock and Soil Mechanics, vol. 31, no. 6, pp. 1809-1812, 2010.

[10] F. Y. Liu, Z. Zhang, and D. Zhou, "Density saturation dependent air water permeability function of unsaturated loess," Chinese Journal of Rock Mechanics and Engineering, vol. 29, no. 9, pp. 1907-1914, 2010.

[11] D. G. Fredlund and H. Rahadjo, Soil Mechanics for Unsaturated Soils, pp. 97-98, John Wiley \& Sons, New York, 1993.

[12] A. T. Corey, "Measurement of water and air permeability in unsaturated soil," Proceedings - Soil Science Society of America, vol. 21, no. 1, pp. 7-10, 1957.

[13] C. H. Benson and M. Gribb, Measuring Unsaturated Hydraulic Conductivity in the Laboratory and field//Unsaturated Soil Engineering Practice, , Special Technical Publication, Reston, 1997pp. 113-168, 68.

[14] S. Huang, D. G. Fredlund, and S. L. Barbour, "Measurement of the coefficient of permeability for a deformable unsaturated soil using a triaxial permeameter," Canadian Geotechnical Journal, vol. 35, pp. 426-432, 1998.

[15] C. J. Miller, "Impact of soil type and compaction conditions on soil water characteristic," Journal of Geotechnical and Geoenvironmental Engineering, vol. 128, no. 9, pp. 733-742, 2002.

[16] M. Vauclin, J. Imbernon, and G. Vachaud, "Comparative analysis of different methods for the determination of unsaturated hydraulic conductivity of North-Central Senegal soils," Agronomie Tropicale, vol. 38, pp. 186-197, 1983.

[17] Y. Mualem, "Anisotropy of unsaturated soils," Soil Science Society of America Journal, vol. 48, no. 3, pp. 505-509, 1984.

[18] M. G. Schaap, F. J. Leij, and M. T. V. Genuchten, "Rosetta: a computer program for estimating soil hydraulic parameters with hierarchical pedotransfer functions," Journal of $\mathrm{Hy}$ drology, vol. 251, no. 3, pp. 163-176, 2001.

[19] S. Taibi, K. V. Bicalho, C. Sayad-Gaidi, and J. M. Fleureau, "Measurements of unsaturated hydraulic conductivity functions of two fine-grained materials," Soils and Foundations, vol. 49, no. 2, pp. 181-191, 2009.

[20] Y. Guo, W. Ni, Z. Kou, Y. Zhao, and Y. Nie, "Experimental study on the permeability of compacted loess," Soil Mechanics and Foundation Engineering, vol. 57, pp. 394-400, 2020.

[21] Y. G. Yao, Y. C. Zhang, X. L. Gao, H. Huang, D. Liu, and $\mathrm{X}$. Hui, "Study on permeability and collapsibility characteristics of sandy loess in northern Loess Plateau, China," Journal of Hydrology, vol. 603, p. 126883, 2021.

[22] Y. L. Nan, Z. K. Zhao, X. Jin, L. Zhang, X. Zhu, and Z. J. Liu, "Permeability coefficient of unsaturated loess and its gaseous and liquid water migration modeling," Advances in Civil Engineering, vol. 2021, Article ID 6689603, 2021.

[23] A. Cihan, J. S. Tyner, and E. Perfect, "Predicting relative permeability from water retention: a direct approach based on fractal geometry," Water Resources Research, vol. 45, no. 4, Article ID W04404, 2009.
[24] K. J. Witt and J. Brauns, "Permeability anisotropy due to particle shape," Journal of the Geotechnical Engineering Division, vol. 109, no. 9, pp. 1181-1187, 1983.

[25] A. Tabbaa and D. M. Wood, "Some measurements of the permeability of kaolin," Géotechnique, vol. 37, no. 4, pp. 499-514, 1987.

[26] H. Daigle and B. Dugan, "Permeability anisotropy and fabric development: a mechanistic explanation," Water Resources Research, vol. 47, p. W12517, 2011.

[27] A. L. Adams, T. J. Nordquist, and J. T. Germaine, "Permeability anisotropy and resistivity anisotropy of mechanically compressed mud rocks," Canadian Geotechnical Journal, vol. 53, no. 9, pp. 1474-1482, 2016.

[28] Standardization Administration of China (Sac), Ministry of Water Resources, China National Standards: Standard for Soil Test Method, Beijing, 2019.

[29] M. T. Van Genuchten, "A closed-form equation for predicting the hydraulic conductivity of unsaturated soils," Soil Science Society of America Journal, vol. 44, no. 5, pp. 892-898, 1980.

[30] D. B. Stephens and S. Heermann, "Dependence of anisotropy on saturation in a stratified sand," Water Resources Research, vol. 24, no. 5, pp. 770-778, 1988.

[31] J. T. Mccord, D. B. Stephens, and J. L. Wilson, "Hysteresis and state-dependent anisotropy in modeling unsaturated hill slope hydrologic processes," Water Resources Research, vol. 27, no. 7, pp. 1501-1518, 1991.

[32] T. R. Green and D. L. Freyberg, "State-dependent anisotropy: comparisons of quasi-analytical solutions with stochastic results for steady gravity drainage," Water Resources Research, vol. 31, no. 9, pp. 2201-2211, 1995.

[33] Y. Mualem, "A new model for predicting the hydraulic conductivity of unsaturated porous media," Water Resources Research, vol. 12, no. 3, pp. 513-522, 1976.

[34] Z. Zhang, F. Y. Liu, J. L. Qi et al., "Represention of anisotropy in unsaturated permeabilities for soils based on pore connectivity-tortuosity parameter," Chinese Journal of Geotechnical Engineering, vol. 40, no. s, pp. 147-152, 2018.

[35] G. E. Laliberte, A. T. Corey, and R. H. Brooks, Properties of Unsaturated Porous media, Colorado State University, Fort Collins, 1966.

[36] Y. Liang, X. L. Xing, T. L. Li, and P. Xu, "Study of the anisotropic permeability and mechanism of $\mathrm{Q}_{3}$ loess," Rock and Soil Mechanics, vol. 33, no. 5, pp. 1313-1318, 2012.

[37] J. Xu, C. Ren, S. H. Wang, J. Gao, and X. Zhou, "Permeability and microstructure of a saline intact loess after dry-wet cycles," Advances in Civil Engineering, vol. 2021, Article ID 6653697, 2021. 